INVESTIGACIÓN/RESEARCH

Recibido: 14/07/2011---Revisado: 15/09/2011 Aceptado: 02/11/2011---Publicado: 15/03/2012

\title{
Aplicación de la teoría de la redacción periodística a la nota de prensa
}

Lorena Busto-Salinas': Universidad de Burgos. España

lbusto@ubu.es

\section{RESUMEN}

Los expertos de la redacción periodística no consideran la nota de prensa un género propio de este ámbito y los manuales de relaciones públicas no han vinculado ambas partes extensamente. Sin embargo, para que esta herramienta sea publicada por un medio de comunicación sin apenas modificación, debe componerse de la misma manera en que lo haría un periodista; es decir, tiene que adecuarse a las directrices de la redacción periodística. En esta investigación se vuelcan estas guías a la elaboración de las notas de prensa para ofrecer unas recomendaciones que sirvan para redactar comunicados más eficaces.

PALABRAS CLAVE: Medios de comunicación - Redacción periodística - Relaciones Públicas - Comunicación externa - Nota de prensa

\section{APPLICATION OF JOURNALIST WRITING THEORY IN PRESS RELEASES}

\begin{abstract}
Journalism experts do not consider the press release a proper genre of the area and the public relations manuals have not linked both extensively. However, in order to be published by the media with the less modification as possible, a press release should be elaborated the same way a journalist would; that is to say, it has to meet journalism writing guides. In this research, these guides have been introduced in press releases writing in order to help elaborating more efficient releases.
\end{abstract}

\footnotetext{
${ }^{1}$ Autor correspondiente:

Lorena Busto-Salinas: Investigadora del FPI. Facultad de Humanidades y Educación. Universidad de Burgos, España.

Correo: 1busto@ubu.es
} 
KEY WORDS: Mass communication - Journalism writing - Public relations - External communication - Press release

\section{INTRODUCCIÓN}

\subsection{La nota de prensa y su vinculación con el periodismo}

La nota de prensa no es considerada por los expertos de la redacción periodística como un género propio de esta disciplina, visto el vacío que existía hace casi dos décadas (León Alonso, 1994, p. 7) y sigue existiendo ahora sobre esta utilidad en la bibliografía referente a la prensa. Sin embargo, las normas de elaboración deben homologarse a las que se usan en la práctica periodística, ya que la forma externa en que se construyen la noticia y la nota de prensa es "exactamente la misma" (León Alonso, 1994, p. 85). En consecuencia, este elemento de los profesionales de la comunicación empresarial debe estructurarse "pensando en cada una de sus partes como si se estuviera redactando una noticia que se va incluir en un medio informativo" (Yanes-Mesa, 2007).

En un estudio sin publicar llevado a cabo en 1979 (General Motors Business) ya se hacía referencia a la elaboración de la nota de prensa tal y como la escribiría un redactor de un periódico. En boca de un editor entrevistado para el estudio:

Las notas deben estar bien documentadas, ser cortas y concisas. Han de estar redactadas lo más parecidas posible a como lo haría un redactor, de tal forma que requiera el mínimo de modificación para su publicación. Este procedimiento eleva el respeto que tienen los medios hacia la empresa y mejorará su efectividad.

$\mathrm{Y}$ es que el periodista "valora que le facilites las cosas, que no le compliques y tener que rehacer enteramente un comunicado mal redactado" (del Río Martínez, 2001, p. 34). A pesar de este consejo, siguen siendo muchas las organizaciones, por muy grandes que éstas sean, que caen en estos errores (del Río Martínez, 2001, p. 34). Un ejemplo de ello lo proporciona una encuesta enviada a 200 editores de diarios estadounidenses, que atestigua que todas las notas enviadas por el gobierno requerían ser editadas o reescritas antes de su publicación. El 50\% de estos profesionales aseguraron que necesitaban una modificación entre bastante profunda y extensa, mientras que el 10\% dijeron que tenían que reescribir por completo el texto (National Newspaper Association, 1979).

Sin embargo, lo que las empresas informativas demandan son notas de prensa "prefabricadas en un estilo de noticia apropiado y que por tanto requiera el mínimo de reelaboración" (Bell, 1991, p. 58). El contenido también debe estar estructurado de tal manera que "fluya en sincronización con los requerimientos del sistema mediático" para conseguir "una mayor probabilidad de entrar en el ambiente de la información 
pública" (Gandy, 1982, p. 57). De esta manera, además, se consiguen notas de prensa con un aspecto más objetivo (Jacobs, 1999, p. 228).

Todo esto se alcanza adaptando la teoría de la redacción periodística a la elaboración de la nota de prensa. En palabras de Walters, Walters y Starr (1994):

En el mundo ideal de los Relaciones-públicas, el periodista no tendría que hacer ningún cambio en las notas que recibe [...]. La manipulación de los elementos sintácticos de una nota de prensa por parte del redactor podría cambiar su significado y, por tanto, el impacto y el valor para esa institución. En consecuencia, los profesionales de las relaciones públicas tienen que mantener esos cambios en el mínimo. Para conseguirlo, el profesional debe escribir la nota como el periodista lo haría, lo que, a su vez, implica conocer lo que el periodista hace ahora con las notas que recibe.

\section{METODOLOGÍA}

La base de la presente investigación se basa en el estudio analítico inductivo a partir de la lectura de los periódicos seleccionados como muestra de la labor profesional de los publirrelacionistas y la necesidad de las agencias de comunicación de disponer de herramientas especiales de comunicación con sus públicos a través de los Medios de Comunicación para Masas mediante herramientas comunicativas ex profeso como la nota de prensa, en especial.

Una vez analizadas las necesidades de los publirrelacionistas tales como comunicados y notas de prensa en especial, se centra este artículo en los contenidos estructurales y semánticos de las publicaciones para extraer las conclusiones que se derivan del compendio formado por las necesidades comunicativas propias de la persuasión publirrelacional y las posibilidades periodísticas.

\section{ANÁLISIS Y DISCUSIÓN}

\subsection{La búsqueda de la noticia}

El primer paso que debe cumplirse antes de componer una nota de prensa es averiguar si el tema principal es realmente noticioso como para que le interese a un medio de comunicación. Esta es la primera premisa de cualquier producto informativo y tanto los periodistas como los investigadores coinciden en señalar la importancia de este aspecto.

Así, un comunicado que tenga la pretensión de colarse entre las noticias de un diario debe contener "información sobre un hecho novedoso que tenga interés para los lectores de los medios a los que se dirige el comunicado", o lo que es lo mismo, debe redactarse en torno a lo que en periodismo se denomina noticia (Grijelmo, 2008, p. 31). Este elemento es el punto de partida y materia prima de cualquier género informativo, es "cualquier información que tenga interés" (Given, 1907, p. 168) o "lo que hará que la gente hable" (C. 
Ross, 1911, p. 43). Martínez Albertos (2002, p. 288) la define como "un hecho verdadero, inédito o actual, de interés general, que se comunica a un público que pueda considerarse masivo, una vez que ha sido recogido, interpretado y valorado por los sujetos promotores que controlan el medio utilizado para la difusión".

En términos generales, Gomis (1991, p. 100) opina que un diario acierta cuando publica un día la noticia que los demás publicarán la jornada siguiente, cuando utiliza una noticia que provocará nuevas informaciones y cuando destaca una noticia que él mismo comenta y que suscitará comentarios en los días siguientes. José Javier Muñoz (1994, p. 96) se muestra más explícito y proporciona en su libro Redacción periodística: teoría y práctica una lista con los elementos más importantes de una noticia según su visión particular. Estos son: oportunidad, diferencia, proximidad, consecuencias, humanidad, conflicto, notoriedad y utilidad.

Para Muñoz, oportunidad es el resultado de la unión de actualidad y novedad, o lo que es lo mismo, "la pertinencia temporal de una información, la cualidad que hace aconsejable o no el contarla y el cuándo contarla". La diferencia es el segundo factor de importancia que señala este autor. Es todo aquello que "se sale de lo normal, lo singular, lo raro (por escaso o por extraño) y lo original". La proximidad, ya sea espacial, afectiva o temática, también es un punto a tener en cuenta por los periodistas, al igual que sucede con las consecuencias de cualquier acontecimiento. La humanidad, o todo aquello que tiene interés humano, constituye un elemento esencial en cualquier noticia periodística. Dentro de este grupo se hallan todos los instintos y los sentimientos. Los pleitos, las polémicas, las guerras, los crímenes, la delincuencia y un largo etcétera conforman lo que Muñoz denomina conflicto. La notoriedad engloba el conocimiento previo de la materia de la que trata una noticia, sus circunstancias y los personajes implicados en ella. El último aspecto más importante de una noticia, según la visión de este profesor, es la utilidad, un elemento que "no se refiere únicamente al mero concepto utilitarista material, sino de mejora para la vida cotidiana y para el desarrollo integral de las personas".

Existen otras fórmulas para determinar si un hecho puede convertirse en noticia. Para Carl Warren (1951), por ejemplo, una noticia debe ser actual, tener proximidad física, que tenga repercusiones futuras, contenga personas relevantes, suspense, rareza, conflicto, sexo, emoción y progreso para la humanidad. La nota de prensa que reúna un mayor número de estas características tendrá más probabilidades de pasar el filtro del periodista.

Otra forma de ahondar en lo interesa a los periódicos y por lo que se puede guiar un profesional a la hora de elaborar una nota de prensa se detalla a continuación (Romano, 1986, p. 48-58):

a) La prensa cubre eventos simbólicos.

b) La prensa cubre a las personas famosas.

c) La prensa cubre aniversarios.

d) La prensa cubre lo posible. 
e) La prensa cubre lo fácil.

f) La prensa cubre temas de buen gusto.

g) La prensa se cubre las espaldas ante los tribunales.

h) La prensa cubre historias que pueden ganar premios.

i) La prensa cubre a los amigos de una manera positiva y a los enemigos de forma negativa.

j) La prensa no cubre las noticias que pueden causar muertes.

k) La prensa no cubre informaciones que causen una mala imagen de personas "cercanas".

1) La prensa no se cubre a sí misma.

m) La prensa no critica las creencias extendidas de la población.

A pesar de todo, resulta conveniente realizar una investigación previa antes de comenzar a enviar notas de prensa para cerciorarse de las noticias que suelen interesar más a cada periódico, ya que no todos suelen publicar las mismas notas de prensa. Por ejemplo, en un análisis de las notas de prensa de la Fundación Atapuerca (Burgos), se observa que los diarios locales tienden a publicar todo tipo de temas con una mayor relevancia, mientras que los nacionales se hacen eco únicamente del asunto más exclusivo que puede ofrecer una entidad (Busto, 2011a). Un estudio previo de los medios de comunicación que se encuentran al alcance de un gabinete de comunicación de una entidad ayuda a mejorar el porcentaje de notas de prensa publicadas y a mantener una relación más efectiva y cordial con los medios de comunicación.

\subsection{La redacción de la información}

Una vez identificada la noticia, el profesional del gabinete de comunicación debe componer la nota de prensa de la misma manera en que un redactor de un periódico escribiría una información. Mientras que normalmente a la noticia se la considera el acontecimiento, la información es el texto que trata sobre ello (aunque hay autores que opinan de manera contraria). Los expertos coinciden en reseñarlo como el género periodístico más rigurosamente objetivo, tanto desde el propósito teórico como desde el lenguaje utilizado y la apariencia formal. Es el "más escueto, más encarnado, más frecuentemente ceñido al puro esqueleto del hecho o acontecimiento que se quiere transmitir" (Martínez Albertos, 2002, p. 288). Se trata, en un sentido amplio, del texto periodístico que "transmite datos y hechos concretos de interés para el público al que se dirigen, ya sean nuevos o conocidos con anterioridad. La información, en sentido estricto, no incluye opiniones personales del periodista ni, mucho menos, juicios de valor" (Grijelmo, 2008, p. 30). Este género debe componerse siguiendo las normas del estilo periodístico, por un lado, y las del estilo informativo, por otro.

\subsubsection{Estilo periodístico}

Armentia \& Caminos (2009, p. 76-77) ofrecen la visión más simplificada del estilo periodístico, al incluir únicamente tres características: claridad, concisión y naturalidad. La primera propiedad implica utilizar palabras y expresiones que puedan ser comprendidas por una persona de cultura media, sea experta en el tema o no. Para 
ello, el vocabulario no debe ser "ni preciosista ni excesivamente técnico", ya que "no puede considerarse un texto como verdaderamente periodístico si obligamos al receptor a interrumpir la progresión normal de su lectura para volver de nuevo sobre el párrafo leído". La concisión implica que las noticias deben escribirse con las palabras que sean exclusivamente necesarias, sin entrar en rodeos o ideas secundarias, y la naturalidad significa prescindir de todo elemento enrevesado, artificioso, complicado o barroco.

El profesor Martínez Albertos (2002, p. 203), por su parte, propone un elenco más amplio para definir las particularidades del lenguaje periodístico. En concreto, el catedrático expone seis notas: corrección, concisión, claridad, captación del lector, lenguaje de producción colectiva y lenguaje mixto. José Javier Muñoz (1994, pp. 167171) incluye un punto adicional, llegando así hasta las siete características: claro, fluido, equilibrado, expresivo, gramaticalmente correcto, adecuado al género y el tratamiento técnico del mensaje y ordenado.

Los libros de estilo de los periódicos o grupos de comunicación también se atreven a señalar sus propias cualidades de estilo. En general, dentro de cada característica ofrecen un mayor número de guías e incluso se menciona algún ejemplo. Son, evidentemente, más prácticos. Exceptuando las características de claridad y concisión, que ya han sido analizadas a través de otros autores, el volumen de Vocento (de Sousa, 2003, pp. 28-31) explica que una noticia debe ser actual, precisa y que se adecúe lo máximo posible a la realidad. También expone que debe ser amena y que resulta conveniente humanizar las informaciones introduciendo personajes.

ABC (Vigara, 2001, p. 161-164) también tiene sus propias normas generales de redacción periodística, recogidas todas ellas en su libro de estilo. En términos generales, coincide con las recomendaciones de Vocento, sobre todo en las características de claridad y precisión. Dejando estos dos aspectos a un lado, ABC destaca que la información debe tener fluidez, armonía, buen gusto y tiene que priorizar la información frente a la opinión.

Álex Grijelmo (2008, p. 623) se sale de la norma tradicional e incluye nuevos aspectos característicos del estilo periodístico. Estos son: claridad, ironía, adjetivo, ordenación lógica, vocabulario, metáfora, sorpresa, paradoja, sonido, humor, ritmo, ambiente, orden y remate. Aun con estas novedades, opina que la claridad y la corrección son las materias primas de cualquier producto que origine la prensa.

\subsubsection{Estilo informativo}

El periodismo engloba varios géneros, tales como la información, la crónica, el reportaje, la entrevista, etc. Cada uno de ellos cuenta, aparte de con el lenguaje periodístico global, con sus características particulares. En el caso de las informaciones, que son los textos a los que se debe asemejar lo máximo posible la nota de prensa, el estilo que deben cumplir es el informativo. Básicamente, este lenguaje lo que busca por encima de todo es "transmitir a los lectores un determinado mensaje en óptimas condiciones de rapidez y eficacia comunicativa" (Martínez Albertos, 2002, p. 225). 
Varios autores se han lanzado a la búsqueda de unas reglas que definan el estilo informativo. Según Dovifat (1959), cuya propuesta resulta ser la más sencilla y una de las más instauradas, el estilo informativo puede resumirse en tres características fundamentales: concisión, claridad y una construcción que llame la atención.

Según el profesor alemán, la primera regla se consigue con una expresión reposada y objetiva de los hechos. Cree que no es el número, sino la elección cuidadosa y certera de las palabras lo que verdaderamente comunica y da vida a las noticias. Insta a redactar mediante frases cortas apoyadas en el núcleo nominal y a evitar muchas conjunciones y relativos. Para lograr la claridad expositiva [el requisito más importante, según Martínez Albertos (2002, p. 222)], se deben utilizar verbos activos y dinámicos, con núcleo nominal, en preferencia en su forma activa. La construcción que llame la atención se consigue, de acuerdo con Dovifat, a través de la riqueza de vocabulario y del empleo colorido y ágil que puede hacerse del léxico.

Martín Vivaldi (2004, p. 396-397) propone un elenco más amplio, de tal manera que define las condiciones de una información bien redactada como veraz, exacta, interesante, completa, clara, breve y rápida.

\subsection{Lenguaje}

Las notas de prensa que se envían a los medios de comunicación social son interceptadas por los correspondientes periodistas del medio, que cumplen una doble misión de receptor-emisor, pero en un último término la información está destinada al ciudadano. Debido a este enredo, el mensaje inicial debe estar meticulosamente elaborado de manera que no se produzca una desviación de la idea principal ni de la argumentación (Yanes Mesa, 2007). Cuidar con esmero el lenguaje que se utiliza en cada comunicado es un elemento clave para evitar esa posible distorsión por parte del redactor.

El primer paso a seguir es utilizar un vocabulario sencillo y claro. Para conseguirlo, se debe huir de "términos incomprensibles para el gran público, ya sea de carácter técnico o de temas que sean dominados por un grupo de 'iniciados'" (Rojas, 2003). En definitiva, no se han de usar palabras pedantes o ampulosas, ni tampoco un vocabulario técnico ni el correspondiente a ninguna jerga. Al contrario, las notas de prensa deben estar redactadas en base al lenguaje periodístico, de tal forma que el redactor no tenga que realizar cambios profundos. Este aspecto es apreciado especialmente cuando no existe tiempo suficiente para modificar la nota o para medios pequeños que no disponen de suficiente personal (Cárdenas, 2000).

Opuestamente a lo que a simple vista puede parecer, un lenguaje sencillo no implica un lenguaje vulgar: "Se trata de utilizar términos comunes que sean asequibles para la gran mayoría, no de palabras 'populacheras', que además no añaden comprensión" (Yanes Mesa, 2007). Y es que, según este autor, es preferible que el mensaje informativo resulte "enormemente claro para su rápido entendimiento" antes que rico desde el punto de 
vista estético: "La información tiene que ser entendida en el acto. Si necesita una relectura es que no ha sido elaborada con la suficiente claridad, por lo que es posible que el léxico utilizado no sea el adecuado, por culteranismo, o el mensaje inapropiado, por conceptismo".

No obstante, un lenguaje simple no implica necesariamente una construcción rígida y monótona; más bien al contrario. Las notas de prensa deben escribirse con una densidad léxica máxima, basándose en "un lenguaje ágil, variado y con ritmo, de manera que el periodista que lo recibe se vea atraído por el texto hasta el final del relato y le convenza de su importancia para ser publicado" (Yanes Mesa, 2007). Todo ello, por descontado, atendiendo a las normas gramaticales y ortográficas que rigen la lengua española.

Además, el responsable de un gabinete de comunicación debe evitar a toda costa los adjetivos, puesto que restan fe en la organización que lo emite. "Frente al lenguaje publicitario, con sus estrategias de persuasión e impacto en el público, el de relaciones públicas debe basarse en la credibilidad de la fuente y en la posibilidad de contrastar los datos que se aportan" (Rojas, 2005, p. 124).

\subsection{Elementos}

\subsubsection{El título}

Los principales manuales de redacción periodística y los libros de estilo de los diarios más importantes de España coinciden en señalar el título como el principal elemento de una información. Se trata de la frase destacada que se coloca en primer lugar en la nota de prensa (Rojas, 2008, p. 126) y sirve para dar a conocer el nombre o asunto de una obra o de cada una de las partes o divisiones de un escrito para captar la atención del lector (Martín Vivaldi, 2004, p. 375). La importancia de esta parte del texto en los periódicos es tal que, según Álex Grijelmo (2008, p. 465), “un diario lleno de magníficos textos ofrecerá una imagen penosa si está mal titulado y apenas resultará atractivo. Por el contrario, un periódico con textos regulares logrará enganchar al lector si los títulos se han escrito con intención o con gracia".

La función principal de los títulos es atraer al lector y sintetizar lo que se desea contarle. El titular y la entradilla deben proporcionar los datos más importantes de la información, de tal manera que el lector se entere de lo que ocurre sin necesidad de acudir al resto de la información (El País, 2007, p. 51). Por esta razón, el titular no puede ser ambiguo ni de difícil comprensión.

Además de esto, tienen que centrar la atención e imponerle su contenido (El País, 2007, p. 51). Estas piezas de la noticia definen la interpretación del texto, así como el tono y la actitud con que el público se enfrentará al artículo. En consecuencia, los titulares no pueden despistar ni orientar de forma distinta al enfoque y a las tesis de la información, por lo que no deben establecer conclusiones que no figuren en el cuerpo. Estos "emanan de la información, del cuerpo del texto, no lo reemplazan, y por lo tanto no deben mencionarse hechos o conclusiones que no estén contenidos en la información" 
(Martínez de Sousa, 2003, p. 32). Es peligroso y, a la larga, desprestigia (Martín Vivaldi, 2004, p. 379).

A pesar de que es imposible dar unas normas generales sobre titulación porque cada periódico posee las suyas (Martínez Albertos, 2002, p. 416), existen unos elementos que están presentes en todos los libros de estilo. De acuerdo con estos manuales, el titular debe ofrecer siempre lo más importante e interesante (Martínez de Sousa, 2003, p. 32). Normalmente, eso suele ser lo que ha pasado, aunque, a veces, es el quién, dónde o cuándo lo que cobra importancia (Martín Vivaldi, 2004, p. 378). En un segundo lugar, el titular también debe llamar la atención del redactor. Esto se puede conseguir mediante la concisión y las apelaciones a lo asombroso y extraño (Martínez Albertos, 2002, p. 416). Otro aspecto relevante es la originalidad, hasta tal punto que algunos autores han llegado a afirmar que sólo este aspecto puede convencer al periodista de que la titulación que ha elegido el gabinete de comunicación debe respetarse en la publicación (Yanes Mesa, 2007).

Otro punto elemental que agradecen los diarios es la brevedad, la claridad y la concisión. Aunque no parece haber un consenso en cuanto al número exacto de palabras que debe conformar un título, la horquilla se sitúa entre las once o trece. Así, Gonzalo Martín Vivaldi (2004, p. 375) explica que los títulos de las informaciones, de las crónicas o de las biografías han de ser informativos, y que conviene emplear once o doce palabras como máximo. Le da la razón Rafael Yanes Mesa (2007), añadiendo que una nota de prensa no debe superar ese número de vocablos si se desea que el periodista publique la noticia. Por su parte, el libro de estilo de El País indica que los títulos, como norma general, no deben superar las trece palabras.

Las posibilidades de que se publique sin modificación alguna se incrementarán aún más si el conjunto de las palabras son asequibles para todo tipo de público (El País, 2007, p. 51), no únicamente para aquellos especializados en esa sección (Grijelmo, 2008, pp. 498-499). Se prefieren palabras exactas antes que generales y los sustantivos antes que los adjetivos (únicamente se adjetiva en los títulos cuando no hay otra forma de resumir un hecho). Esto evita las exageraciones, tan repudiadas en los titulares, y el afán publicitario de atraer la atención (Martín Vivaldi, 2004, p. 379). Los periodistas se sentirán distanciados de las notas de prensa con aquellos títulos que utilicen palabras técnicas o especializadas y pasarán a la siguiente nota para buscar una que se adapte mejor a las necesidades informativas. Además, la mayoría de los periódicos prefieren títulos con un verbo, preferiblemente de acción, en tiempo presente y con una afirmación mejor que con una negación o pregunta (Grijelmo, 2008, p. 466).

En cuanto al formato, los manuales de relaciones públicas instan a titular en diferente formato que el resto de la información. De esta manera, proponen una frase en mayúsculas y negrita (del Río Martínez, 2001, p. 183), centrada y a una letra de mayor tamaño (Rojas, 2003). Otros, como Rafael Yanes Mesa (2007), a pesar de compartir las ideas anteriores, rechazan la idea de utilizar letras mayúsculas. Los libros de estilo, por su parte, no especifican el formato exacto de los titulares, si bien es cierto que en los de información general abundan las letras minúsculas. 
Los elementos que, por norma general, tienen que evitarse al componer el título de una nota de prensa se detallan a continuación: signos, cursivas, siglas, adverbios de tiempo, orden incorrecto, apelaciones, paréntesis, declaraciones textuales, repeticiones, hermetismo, comienzos institucionales y copias de otros títulos.

\subsubsection{Antetítulo y subtítulo}

En los medios impresos, un título puede estar acompañado de cintillo, antetítulo, subtítulo y sumario (El País, 2007, p. 51), atendiendo a la importancia y extensión de la noticia. En una nota de prensa, sin embargo, únicamente tienen cabida el antetítulo y el subtítulo, puesto que el cintillo se utiliza cuando todos los temas de una misma página son comunes y el sumario cuando el artículo es "muy amplio" (El País, 2007, p. 52).

Algunos autores son partidarios de utilizar en alguna ocasión antetítulos o subtítulos en las notas de prensa (Rojas, 2003; Yanes Mesa, 2007), aunque instan a seleccionarlos meticulosamente porque "pueden provocar una dispersión indeseada, pueden sustituir al titular que se ha elegido" (Yanes Mesa, 2007). De hecho, su inclusión en el comunicado debe conllevar cambios incluso en la tipografía: "[La entradilla] puede destacar tipográficamente con un tamaño menor que el titular pero mayor que el resto del texto. Sin embargo, cuando se utilizan subtitulos, el lead debe formar parte del cuerpo de la nota de prensa" (Yanes Mesa, 2007).

El antetítulo, que se coloca antes del título y que casi siempre tiene más palabras que aquel (El País, 2007, p. 34), sirve como explicación o ampliación de la noticia (El País, 2007, p. 52-53) o para atraer la atención del lector (Armentia y Caminos, 2009, p. 160). El subtítulo, al contrario que el antetítulo, se coloca después de la frase principal. Su inclusión se justifica "por la conveniencia de aportar algún dato importante que no tiene cabida en la brevedad del título" (Muñoz, 1994, p. 182). De esta forma, cumple una misión de apoyar, complementar y explicar el título. Para conseguir este fin de una manera escueta, debe estar formado por "una sola frase, breve y simple para que la idea quede clara en una lectura rápida" (Martínez de Sousa, 2003, p. 33). Cada uno de estos elementos que forman parte del titular deben redactarse con total autonomía, de manera que "la supresión de alguno de ellos no impida la comprensión del conjunto" (El País, 2007, p. 52).

\subsubsection{Lugar y fecha de edición}

Uno de los elementos imprescindibles en cualquier tipo de nota de prensa es el lugar donde se origina y la fecha de emisión. Estos datos suelen introducirse después del titular y antes del primer párrafo. En algunos casos, incluso, es frecuente indicar también la hora de envío cuando se despachan en el día varios comunicados y actualizaciones sobre el mismo tema (Rojas, 2003).

A pesar de que puedan parecer banales, estos datos ofrecen varios beneficios. Por un lado, ayudan al redactor a establecer el interés de la nota, puesto que no otorgará la misma atención a un acontecimiento si se produce en su ciudad que en otra localidad 
de otro país diferente. Lo mismo ocurre con la fecha: si se trata de un evento acaecido días atrás en vez de en la misma jornada perderá inmediatez en el tiempo y, por tanto, interés informativo (Rojas, 2005).

Otra de las principales ventajas es que otorga credibilidad al producto (Rojas, 2003), ya que "los periodistas siempre quieren saber de dónde viene la información que van a aportar a su audiencia" (Rojas, 2005). Finalmente, sirven de gran ayuda tanto para los periodistas que en un futuro quieran utilizar esa información de archivo, como para el responsable que la escribió si más adelante necesita recuperarla. Los investigadores también agradecen su inclusión en cada comunicado, ya que asegura el momento y lugar exacto en el que ocurre un acontecimiento a analizar (Rojas, 2005; Busto, 2011b).

\subsubsection{El lead o entradilla}

El primer párrafo es uno de los elementos más importantes del texto informativo. Denominado según autores entrada, entradilla, comienzo, arranque o lead, completa junto con el titular "una de las partes esenciales en la redacción de las noticias" (Armentia y Caminos, 2003, p. 81), máxime en el caso de las informaciones, donde este elemento adquiere "una importancia capital y decisiva" (Martínez Albertos, 2002, p. 291).

Martínez Albertos lo define como "el párrafo inicial, que se distingue y en algunos casos se separa incluso tipográficamente del resto del trabajo periodístico dedicado a descubrir escueta y objetivamente un hecho". Sus líneas deben contener los "principales datos de interés y de justificación de la noticia, que serán desarrollados en el resto de la información" (Vigara, 2001, p. 166). Se corresponde, por tanto, con un "resumen de lo más importante de la noticia" (Martín Vivaldi, 2004, p. 395) o con un "texto narrativo quintaesenciado" (Martínez Albertos, 2002, p. 293).

En el caso de las notas de prensa, adquiere una gran importancia porque "muchos periodistas ocupados no leerán más texto del comunicado si el primer párrafo no proporciona toda la información pertinente" (Paul, 2001). Le da la razón Rojas (2005): "Si el primer párrafo es demasiado largo y farragoso, los periodistas no pasarán de éste, y aunque el resto de la nota sea interesante, ellos nunca lo sabrán". Para evitar que el documento acabe en la papelera de reciclaje del ordenador, también se aconseja sortear los comienzos con una narración o desde una perspectiva histórica, así como alejarse de la escritura política y centrarse en el aspecto social (Paul, 2001).

Los expertos de los gabinetes de prensa aconsejan en el lead expresar el contenido más relevante de la nota y el tono general de la información de la manera más clara y exacta posible (Yanes Mesa, 2007). "Al lector se le debe conducir con mimo, sin obligarle a sobreesfuerzos", afirma Álex Grijelmo (2008, p. 42). Además, no debe ocupar demasiado espacio, por lo que Yanes Mesa insta a proporcionar "la mayor cantidad de información utilizando el menor número posible de palabras". Este autor indica que nunca puede superar "las 30 o 35 palabras", mientras que Rojas (2005) opina que la entradilla debe quedar resuelta en cinco o seis líneas, en no más de diez o doce palabras por frase. Esta 
última estimación se acerca más a lo que concreta el libro de estilo de El País (2007, p. 37), que indica que la "extensión ideal" son "unas 60 palabras".

La entradilla debe escribirse "lo suficientemente completa y autónoma como para que el lector conozca lo fundamental de la noticia, pero en el siguiente párrafo debemos tener descontado lo que se haya narrado ya". En otras palabras, ha de ser "autosuficiente": el lector debe conocer lo fundamental de la noticia leyendo únicamente esta primera división (Armentia \& Caminos, 2009, p. 175).

Un buen arranque de un texto informativo debe cumplir dos fines principales: situar al lector ante los elementos fundamentales de una noticia y captar y mantener su atención (Armentia \& Caminos, 2009, p. 177). Es decir, aparte de relatar los hechos más importantes de la información tiene que suscitar la curiosidad del lector, de tal modo que le obligue a continuar leyendo todo el texto (Armentia \& Caminos, 2003, p. 81-82).

Para alcanzar estos objetivos, el profesor Martín Vivaldi (2004) expone de manera llana las premisas que debe tener en mente cualquier persona que pretenda escribir un producto informativo, incluidos los profesionales de los gabinetes de comunicación a la hora de redactar una nota de prensa: decir algo (la información primordial), rápidamente (sin detalles) y con claridad (de manera sencilla).

La forma tradicional de elaborar una entradilla se denomina "cinco $W$ " y se corresponde con "la explicación en ese párrafo inicial de los elementos que responden a las preguntas: quién, qué, cuándo, dónde y por qué" (Armentia \& Caminos, 2003, p. 84). De acuerdo con Martínez Albertos (2002, p. 293), esta práctica "permite alcanzar un alto grado de eficacia operativa". Martín Vivaldi introduce un sexto elemento, el cómo, aunque algunos autores, como Carl Warren (1951), opinan que esta cuestión está ya contenida en el apartado qué (Martínez Albertos, 2002, p. 293).

No todas las preguntas adquieren la misma relevancia en las informaciones, sino que siempre hay una que destaca por encima de otras. Es esa la que obligatoriamente debe incluirse en el primer párrafo, mientras que el resto puede relegarse a las siguientes divisiones que formen parte del lead. Habitualmente, las cuestiones primordiales atañen al qué y al quién. El cuándo y el dónde, sin embargo, gozan de una menor notoriedad, sobre todo en el caso de la prensa, que recoge las noticias más tardíamente que Internet, la radio o la televisión. Finalmente, el por qué forma más parte del periodismo de interpretación que del puramente informativo, por lo que no siempre se incluye (Armentia \& Caminos, 2003, p. 85).

No obstante, la práctica tradicional de incluir obligatoriamente las cinco preguntas (en algunos casos seis, como se ha visto) en el primer párrafo está dejando paso a nuevos estilos de arranque que tienen cada vez más cabida en los periódicos. Así, El País (2007, p. 37) explica que el lead no debe contener "necesariamente (aunque sí es conveniente) las clásicas respuestas a las preguntas qué, quién, cómo, dónde, cuándo y por qué". Continúa explicando: "Estas seis respuestas pueden estar desgranadas a lo largo de la información -lo cual requerirá dos o, quizá, tres párrafos-, pero siempre según la mayor o 
menor importancia que cada una de ellas tenga en cada caso". Álex Grijelmo (2008, p. 34-36), por su parte, incluye nuevas cuestiones "imprescindibles", aparte de las tradicionales. Estas son según quién, para qué (o con qué consecuencias) y cuánto (número de sujetos o personas implicadas).

Como resultado de esta separación respecto a la norma tradicional de las $5 \mathrm{~W}$, han ido apareciendo nuevas clases de leads, cada uno de ellos con sus correspondientes características, como el arranque indirecto o aplazado y el interpretativo (Armentia \& Caminos, 2003, p. 87-88; 2009, p. 188-191) o, según la división de Álex Grijelmo (2008, p. 38-41), la entradilla literaria, de agencia, institucional o de frase inicial muy corta.

En el caso de las notas de prensa, lo más adecuado es inclinarse por el arranque directo, ya que supone la emisión de un único hecho de la forma más completa posible, dejando al periodista cualquier análisis que él crea conveniente. Hay que tener en cuenta que muchos editores no suelen pasar del primer párrafo si no les resulta atractiva la noticia (Paul, 2001; Rojas, 2005), por lo que se tienen que ofrecer en las primeras líneas los elementos más destacables del acontecimiento, alejándose de cualquier artificio valorativo del profesional del gabinete de comunicación.

A pesar de todo, debido al fuerte impulso de los arranques interpretativos en los medios de comunicación (Armentia \& Caminos, 2009, p. 191), y del "en ocasiones aburrido periodismo informativo tradicional" (Armentia \& Caminos, 2003, p. 87), algunas veces pueden ser preferibles otros tipos de arranques. En todo caso, es necesario incluir en el lead el elemento principal de la información, que suele coincidir con el qué de las 5 W. Álex Grijelmo (2008, p. 38) opina que "una entradilla no sería válida si no contuviera el hecho noticioso en si", ya que "introducir documentación o descripciones en la entradilla no debe significar que con ello se arrincone la idea que figura en el titular".

\subsubsection{El cuerpo}

Después de la entradilla continúa el grueso del texto, o lo que es lo mismo, el cuerpo de la información. Este debe estructurarse en diferentes párrafos, atendiendo normalmente a la longitud de la nota de prensa y a las ideas principales de las que se disponga. Los párrafos deber ser completos y tener autonomía por sí solos, de manera que cada uno tenga unidad por sí mismo y no quede cojo o falta de alguna explicación (El País, 2007, p. 39). De esta forma, se asegura que la comprensión "no quede incompleta si se deja de leer en cualquier momento" (Martínez de Sousa, 2003, p. 35). Esto se consigue escribiendo cada división como si fuera la última, de tal forma que "permita cortar y reajustar el texto sin problemas y con rapidez en el caso de que sea necesario" (El País, 2007, p. 39). Utilizar frases cortas y expresar en cada una de ellas una sola idea es otro modo de asegurarse un texto "claro, directo, exacto y conciso", según Vocento (Martínez de Sousa, 2003).

Sin embargo, no deben existir cambios bruscos entre los párrafos de una nota de prensa; eso desalentaría al redactor a seguir leyendo uno detrás de otro. Para 
solucionar esta incongruencia, se recomienda "unir con suavidad, mediante las partículas apropiadas, las ideas afines". Y es que "cada parte de un artículo, reportaje o crónica [al igual que sucede con la nota de prensa] ha de ser consecuencia lógica de la parte anterior", se menciona en el libro de El País (2007).

Es en el cuerpo de la noticia donde se desarrolla la información "con todo tipo de elementos complementarios; incluye los datos que no figuran en la entrada, explica los antecedentes y apunta las posibles consecuencias" (El País, 2007, p. 38). Sin embargo, esto no significa que se deban inflar las líneas con un sinfín de datos. Por el contrario, "hay que buscar una cadencia que no dé la sensación de barullo" (Grijelmo, 2008, p. 53).

No hay una extensión fija en torno al cuerpo de la información, ya que depende del espacio que se reserve en cada periódico según el interés de la noticia y de los datos que se posean de ella. Sin embargo, como norma general, las notas de prensa no deben ocupar más de una página (Cárdenas, 2000; Paul, 2001). Algunos, incluso, lo cifran en una media de 200 palabras (Walters et al., 1994). El País (2007, pp. 38-39), en cambio, considera que la entrada y el cuerpo de la información no deben superar, "salvo casos excepcionales", las 900 palabras y recomienda no emplear más de 100 palabras por párrafo.

El cuerpo debe estructurarse según lo que Carl Warren (1951) denomina relato informativo, que consiste en proporcionar los hechos más importantes al comienzo de la narración. Armentia \& Caminos (2009, pp. 199-201) la llaman estructura decreciente y se corresponde con la designada pirámide invertida. Tal y como apunta Warren, se trata de elaborar la información de manera contraria a la estructura creciente, es decir, situando en un primer plano los datos más importantes en detrimento de los secundarios, que se van desgranando a lo largo del texto según su importancia.

Este esquema "facilita la lectura de los elementos esenciales de la información ya que el lector sabe que en los primeros párrafos hallará los contenidos más importantes de la noticia", dicen Armentia y Caminos $(2009,202)$. Este aspecto es importante en una época en la que abundan las informaciones y los canales de acceso a ellas y en la que escasea el tiempo para leer cada una de las noticias.

También es un buen método para jerarquizar todos los datos de la noticia y así ofrecer un orden comprensible. Desde el punto de vista pedagógico, esta ventaja permite a los alumnos y aprendices formarse en la estimación de los datos (Armentia y Caminos, 2009, p. 203).

Sin embargo, el esquema tradicional de la pirámide invertida se ha visto cuestionado desde que en 1980 un manual de redacción discutiera por primera vez su necesidad (Sánchez, 1993). En efecto, Brooks, Kennedy, Moen y Ranly (1980) dedican dos apartados en el libro News Reporting and Writing a explicar las alternativas que poseen los redactores al orden decreciente. Según destaca José Francisco Sánchez (1993) sobre la opinión de los estadounidenses, esta organización "no anima a los lectores a terminar la noticia; normalmente los lectores ya han recibido esa noticia a través de la radio o de la 
televisión y, precisamente, en forma de pirámide invertida". La originalidad es otro aspecto que merma al utilizar la estructura de la pirámide invertida: "Induce al lector a leer menos, apagando enseguida su curiosidad y habituándolo a la superficialidad" (Gregorio, 1966).

Desde entonces, el sistema de la pirámide invertida tiene muchos detractores, sobre todo en el sur de Europa, pero también en Estados Unidos (Armentia \& Caminos, 2003, p. 93). La principal queja reside en que los beneficios que otorgaba en el pasado ya no tienen vigencia en la actualidad, debido primariamente a los cambios tecnológicos vinculados con los medios de comunicación (Sánchez, 1993). Según Álex Grijelmo (2008, p. 33):

Tuvo su razón de ser cuando los periódicos se componían en plomo y el cálculo de líneas nunca resultaba exacto [...]. Hoy en día el uso del ordenador o computadora ha resuelto este problema. Hace veinte años, primero se escribía la noticia y después se le encontraba un hueco. El diseño moderno de los periódicos ha invertido el orden: primero se busca un hueco y luego se escribe la noticia.

No obstante, esto no significa que el esquema de la pirámide invertida haya dejado de constituir un sistema válido, sino que ahora hay sitio para varias estructuras.

Probablemente [la pirámide invertida] se reservará sólo para aquellos asuntos que por su peculiar naturaleza lo requieran: noticias de resultados, noticias de última hora de las que no es posible conseguir todas las circunstancias -las denominadas, en el ámbito anglosajón, breaking news- y notas muy breves, principalmente", opina Sánchez (1993). Pero parece ser que será difícil que desaparezca por completo. Y es que, en palabras de Álex Grijelmo (2008, p. 33), "esta técnica sigue constituyendo una buena manera de escribir la noticia, porque implica orden $\mathrm{y}$, a la vez, obliga a situar por delante aquellos hechos o datos que atraerán el interés del lector.

La nota de prensa, al intentar proporcionar datos con la mayor objetividad y claridad posible, debe atender a esta fórmula.

\subsubsection{Contextualización}

Muchas noticias que aparecen en la prensa incluyen datos adicionales que ayudan a los lectores a comprender su contexto. Esta clase de información, denominada en ocasiones background por su término inglés, puede proporcionar aclaraciones de diferentes tipos; a saber, los antecedentes de un conflicto entre países, los asistentes a una firma entre empresas o el número de situaciones similares que se han producido hasta ese momento.

En las notas de prensa también es conveniente introducir algunas líneas con el fin de situar al redactor en el ambiente de la noticia. De esta manera, el periodista se 
beneficia de un texto para orientarse y sentirse más cómodo con la información y, a la vez, obtiene un recurso de archivo para incluir en el producto periodístico final si lo cree conveniente.

En una nota de prensa, este tipo de datos se pueden incorporar de dos formas. Una, denominada tie-in, o cuello, consiste en:

situar inmediatamente después del lead un párrafo que permita recordar al lector la vinculación de este hecho con otras noticias ya sabidas -pero tal vez olvidadas-: datos biográficos más destacados del protagonista o protagonistas, antecedentes del hecho, acontecimientos analógicos ocurridos con anterioridad, etcétera" (Martínez Albertos, 2002, p. 294).

El segundo método se denomina párrafo de contexto o relato de antecedentes. Estas frases, al contrario de lo que sucede con el tie-in, se colocan al final del contenido. Sin embargo, persiguen el mismo objetivo: "Ayudar al lector a ubicar la noticia en el contexto que la circunda" (Armentia \& Caminos, 2009, p. 203).

\subsection{Datos de contacto}

En algunas ocasiones, a pesar de que una nota de prensa está correctamente elaborada, un periodista puede necesitar más datos, obtener declaraciones de algún experto o elaborar la noticia desde otro punto de vista. Esta petición debe quedar servida rápidamente, ya sea mediante una simple llamada de teléfono o el envío de un correo electrónico. Esta facilidad conlleva una ventaja importantísima sobre el primer objetivo de un comunicado: "Ayuda de manera importante a que la información promovida por la nota de prensa sea mejor considerada y con mayores posibilidades de obtener cobertura mediática" (Rojas, 2008, pp. 128-129), ya que "el contacto personal ofrece la posibilidad de explicarlo de forma detallada" (Yanes Mesa, 2007).

Por un lado, es imperativo mostrar el nombre y el número de contacto de la persona encargada del gabinete de comunicación (Cárdenas, 2000) y, por otro, la de algún experto que pueda opinar o ampliar de primera mano la información que contiene la nota de prensa. La persona o personas propuestas como contacto deben, por una parte, conocer la información requerida y, por otro lado, explicar y presentarla de manera adecuada (Ashcroft, 1994).

Se debe dejar toda la información de contacto que sea posible (Rojas, 2003), a saber: nombre, cargo, teléfono directo o extensión y fax (Ashcroft, 1994). Tampoco hay que olvidarse de Internet, por lo que se ha de proporcionar el correo electrónico, la página web y el blog (Rojas, 2005, p. 116). Otros autores también proponen incluir la dirección postal (Paul, 2001). 


\subsection{Información básica de la entidad}

No existen demasiadas referencias bibliográficas sobre la posible inclusión en la nota de prensa de datos referentes a la organización de la que emerge la noticia. Sin embargo, son bastantes las entidades que proporcionan esta clase de datos. Alcoceba Hernando (2010), por ejemplo, en su análisis de la comunicación del Instituto de la Juventud (Injuve), observa que "la mayor parte" de las notas ofrecen "información interna de la institución, o información sobre sus actividades externas relacionadas con otras organizaciones sociales".

Estos datos, denominados a través de su término inglés boilerplate (que puede ser utilizado una y otra vez sin necesidad de cambios), son un elemento imprescindible que debe incluirse en cualquier nota, según Rojas (2005) y María Ross (2010, p. 109). El primer autor habla de ellos como la "información que expone brevemente el nombre de la organización, dirección de página web, origen, posicionamiento, características, etiqueta -caso que cotice en bolsa-, y hasta sus objetivos". La directora de la consultora de branding y marketing Red Slice, por su parte, los considera "el descriptor de la compañía, con algunos otros datos metidos dentro, como el año en que fueron fundadas, la ubicación, y tal vez el número de tiendas". "Sus líneas -añade- a veces incluyen el número de teléfono del encargado de ventas o la dirección del sitio web".

Este párrafo suele colocarse después del cuerpo, a un tipo de letra diferente y a un menor tamaño para diferenciarlo del resto de la nota (Rojas, 2003). De esta manera, se puede entrar desde el comienzo del texto "de lleno en la carne de la noticia" (M. Ross, 2010, p. 109).

A pesar de que los autores mencionados tratan este párrafo como un elemento repetitivo en cada una de las notas que envía un entidad, es recomendable variar algún dato y la estructura cada cierto tiempo (o en cada una de ellas si el profesional dispone de tiempo suficiente), de tal manera que se exponga la misma información pero de diferente forma para que el párrafo no resulte repetitivo. De este modo, aparte de constituir un elemento de documentación para el periodista -para el que no se necesita variar su contenido-, también se convierte en unas líneas que pueden utilizarse en el periódico como contexto para los lectores -en cuyo caso sí es inevitable una modificación en cada número-.

\section{CONCLUSIONES}

La nota de prensa no es considerada un género propio de la teoría periodística. Además, los expertos de relaciones públicas no han vinculado ambas partes completa y extensamente. Pese a ello, esta herramienta de los gabinetes de comunicación ha de componerse de la misma manera en que lo haría un periodista con el fin de que posea más posibilidades de publicación. En consecuencia, se debe volcar la teoría de la redacción periodística a la elaboración de las notas de prensa. 
En primer lugar, se ha escribir sobre un elemento realmente noticioso, bien sea porque contenga algún aspecto de utilidad, de conflicto, de rareza o de consecuencias, entre otras cosas. El lenguaje debe ser sencillo y claro, sin artificios. El titular tiene que ser breve y relatar lo más destacable del suceso, al igual que la entradilla. Con estos dos elementos, el periodista debe enterarse de lo que ocurre sin necesidad de acudir al resto del texto. En el cuerpo de la información se desgranan los detalles de la noticia de mayor a menor importancia, hasta que, al final, se incluye algún párrafo de contexto o de información sobre la entidad.

Con notas de prensa que se asemejen más al tipo de información que publica cada medio de comunicación, ambas partes salen favorecidas: los gabinetes de prensa consiguen comunicados con mayores posibilidades de publicación para lograr sus fines y los medios de comunicación obtienen fuentes de información más útiles para llenar sus canales diariamente.

\section{REFERENCIAS}

Alcoceba, J. A. (2010). Análisis de las notas de prensa institucionales y su visibilidad en la prensa, en Revista Latina de Comunicación Social, n ${ }^{0}$ 65, p. 354-367.

Armentia, J. I. \& Caminos, J. M. (2003). Fundamentos de periodismo impreso. Barcelona: Ariel.

Armentia, J. I. \& Caminos, J. M. (2009). Redacción informativa en prensa. Barcelona: Ariel.

Ashcroft, L. S. (1994). Effective press releases, en Library Management, 8 (15), 24-27.

Bell, A. (1991). The language of news media. Oxford: Blackwell.

Brooks, Brian; Kennedy, George; Moen, Daryl \& Ranly, Don (1980). News reporting and writing. Nueva York: St. Martin Press.

Business and the news media, what are the roles of each? (1979). Detroit: General Motors, Inc.

Busto-Salinas, L. (2011a). Diferencias de tratamiento de las notas de prensa según el ámbito geográfico de los periódicos, en Requeijo-Rey, P. \& De Haro-De San Mateo, M. V. (coord.): Estudio, Innovación y desarrollo de proyectos en comunicación social en el EES (p. 27-45). Madrid: Visión Libros.

Busto-Salinas, L. (2011b). Eficacia de la nota de prensa en la comunicación institucional. El caso de la Fundación Atapuerca. Trabajo de investigación para la obtención de la Suficiencia Investigadora en la Universidad de Burgos. Burgos: Universidad de Burgos. 
Cárdenas, M. L. (2000). Gabinetes de prensa municipales en la provincia de Sevilla: la información como servicio local. Sevilla: Diputación de Sevilla.

De Gregorio, D. (1966). Metodología del periodismo. Madrid: Ediciones Rialp.

De la Serna, V. (1996). El Mundo, libro de estilo. Madrid: Ediciones Temas de Hoy.

Del Río-Martínez, M. (2001). De la nota de prensa al gabinete de comunicación en Internet, en Del Río-Martínez, M. (Ed.). Gabinetes de prensa: la comunicación en las instituciones y en las empresas. Santander: Parlamento de Cantabria.

Dovifat, E. (1959). Periodismo. México: UTEHA.

Editors polled on acceptability of news releases (1979). Editor \& Publisher. p. 30.

Gandy, O. H. (1982): Beyond agenda setting: information subsidies and public policy. Nueva York: Ablex Publishing Corporation.

Given, J. L. (1907). Making a newspaper. Nueva York: Henry Holt and Company.

Gomis, L. (1991). Teoría del periodismo: cómo se forma el presente. Barcelona: Paidós.

Grijelmo, Á. (2008). El estilo del periodista. 16ª edición. Madrid: Taurus.

Jacobs, G. (1999). Self-reference in press releases, en Journal of Pragmatics, $\mathrm{n}^{\circ}$. 31, vol. 2, p. 219-242.

Libro de estilo El País. 20a edición (2007). Madrid: El País S.L.

León-Alonso, M. R. (1994). La nota de prensa: un modelo de comunicación institucional. Tesis doctoral inédita. Sevilla: Universidad de Sevilla.

Manoff, R. K. \& Schudson, M. (Eds.). Reading the news: a pantheon guide to popular culture. Nueva York: Pantheon Books.

Martín-Vivaldi, G. (2004). Curso de redacción: Teoría y práctica de la composición y del estilo. $33^{\mathrm{a}}$ edición, $4^{\mathrm{a}}$ reimpresión. Madrid: Paraninfo.

Martínez-Albertos, J. L. (2002). Curso general de redacción periodística: lenguaje, estilos y géneros periodísticos en prensa, radio, televisión y cine. $5^{\mathrm{a}}$ edición, $2^{\mathrm{a}}$ reimpresión. Madrid: Thompson.

Martínez-De Sousa, J. (2003). Libro de estilo Vocento. Gijón: Ediciones Trea.

Muñoz, J. J. (1994). Redacción periodística: teoría y práctica. 2a edición. Salamanca: Librería Cervantes. 
Paul, C. C. (2001). The power of the press release, en Civil Engineering, (71), 64-65.

Rojas, O. (2003). La nota de prensa, en Razón y Palabra, (32).

Rojas, O. (2005). Relaciones públicas: La eficacia de la influencia. Madrid: Escuela Superior de Gestión Comercial y Marketing (ESIC).

Rojas, O. (2008). Relaciones públicas: la eficacia de la influencia. $2^{a}$ edición. Madrid: Escuela Superior de Gestión Comercial y Marketing (ESIC).

Romano, C. (1986). What? The grisly truth about bare facts, en Manoff, R. K. \& Schudson, M. (Eds.). Reading the news: a pantheon guide to popular culture. Nueva York: Pantheon Books.

Ross, Ch. (1911). The writing of news: a handbook with chapters on newspaper correspondence and copy reading. Nueva York: Henry Holt and company.

Ross, M. (2010). Branding basics for small business: how to create an irresistible brand on any budget. Nashville, Indiana: Norlightspress.Com.

Sánchez, J. F. (1993). La pirámide invertida: caída de un mito, en Cuadernos de información, (8), 23-67.

Vigara, A. M. (2001). Libro de estilo de ABC. (2 edición). Barcelona: Ariel.

Walters, T. N.; Walters, L. M. \& Starr, D. P. (1994). After the highwayman: syntax and successful placement of press releases in newspapers, en Public Relations Review, n 20, vol. 4, p. 345-356.

Warren, C. N. (1951). Modern news reporting. Nueva York: Harper.

Yanes-Mesa, R. (2007). La nota de prensa como género de la comunicación política, en Espéculo: Revista De Estudios Literarios, (36) 45-89.

\section{Lorena Busto Salinas}

Licenciada en Comunicación Audiovisual con premio extraordinario por la Universidad de Burgos, lugar donde ha obtenido el Diploma de Estudios Avanzados con un trabajo sobre la efectividad de la nota de prensa. Becaria FPI, forma parte del grupo de investigación Comunicación, Difusión y Publicidad de la Cultura y del Patrimonio (CAYPAT) de la Universidad de Burgos, con el que ha participado en varios contratos de $\mathrm{I}+\mathrm{D}+\mathrm{i}$ sobre la divulgación del patrimonio y ha contribuido en la redacción de los libros Un siglo de fotografía en Burgos. 1840-1940 y El Patrimonio Histórico de Castilla y León. Tradición y Cultura. 